\title{
Application of COSMO-RS Method for the Prediction of Liquid-Liquid Equilibrium of Water/n-Dodecane/1-Butanol
}

\author{
S. Balasubramonian, Shekhar Kumar, D. Sivakumar, and U. Kamachi Mudali \\ Reprocessing R\&D Division, Reprocessing Group, Indira Gandhi Centre for Atomic Research, Kalpakkam 603102, India \\ Correspondence should be addressed to Shekhar Kumar; shekhar@igcar.gov.in
}

Received 2 December 2013; Accepted 19 December 2013; Published 5 February 2014

Academic Editors: G. L. Aranovich and F. Martínez

Copyright (C) 2014 S. Balasubramonian et al. This is an open access article distributed under the Creative Commons Attribution License, which permits unrestricted use, distribution, and reproduction in any medium, provided the original work is properly cited.

The liquid-liquid equilibrium (LLE) for the system water-dodecane-butanol was estimated using the UNIQUAC model. In the UNIQUAC model interaction parameters were estimated from the vapor-liquid equilibrium (VLE) and LLE data of their constituent binary pairs. The water-dodecane-butanol LLE was experimentally measured at $298.15 \mathrm{~K}$. Phase stability constraints were taken into account while calculating the binary interaction parameters from the mutual solubility data. The COSMO-RS method was used to estimate the activity coefficient in the miscible binary pair. The ternary LLE composition was predicted using the experimental VLE data as well as using the COSMO-RS calculated activity coefficient data along with the experimental mutual solubility data. In the latter case the root mean square deviation (RMSD) for the distribution of butanol between aqueous and organic phase is $0.24 \%$. The corresponding UNIFAC model prediction is $7.63 \%$.

\section{Introduction}

Extraction of uranium and plutonium from the spent nuclear fuel using PUREX method employs tributyl phosphate (TBP) as the extractant and dodecane as the diluent. During solvent extraction TBP and dodecane undergo hydrolytic and radiolytic degradation and form dibutyl phosphate, monobutyl phosphate, butanol, and several other organic compounds [1]. In order to understand the distribution of these compounds in the PUREX process stream their liquid-liquid equilibrium (LLE) behavior between the aqueous and organic phase must be known. The accurate prediction of LLE using the limited amount of experimental data was investigated by several researchers [2-6]. Anderson and Prausnitz [2] described the application of UNIQUAC model for the prediction of LLE. The type II ternary systems which have two partially miscible binaries can be predicted using the binary parameter quite accurately. Magnussen et al. [3] reported separate parameter table for the prediction of LLE using UNIFAC group contribution model. Recently COSMO-RS model reported by Klamt and Eckert $[6,7]$ for the prediction of fluid phase thermodynamic properties is gaining importance to predict LLE. Several authors used COSMO-RS method to predict
LLE of system containing water, hydrocarbon, alcohols, and ionic liquids [8-10].

The various excess Gibbs energy model such as NRTL, UNIQUAC, and UNIFAC can be used to predict the multicomponent LLE. These models contain the interaction parameters which are usually estimated from the binary experimental data. The miscible binary pair interaction parameters were estimated from VLE data. Similarly for partially miscible pair mutual solubility data were used to estimate the interaction parameter. Islam et al. [11] proposed universal set of parameters for predicting both VLE and LLE. The hexane-butanol-water ternary LLE was predicted using this universal set of parameters. The UNIQUAC surface area parameter was expressed as the linear function of concentration to improve the prediction of ternary LLE [12]. According to Anderson and Prausnitz [2] reasonable binary VLE data is sufficient to predict the type II ternary LLE using UNIQUAC model. In this work miscible pair activity coefficient data estimated using COSMO-RS method was used to predict the ternary LLE along with the experimental mutual solubility data. Thus by reducing the experimental data required in the prediction of LLE. The COSMO-RS generated activity coefficient data was used to estimate 
TABLE 1: The pure component density and refractive index measured at $298.15 \mathrm{~K}$.

\begin{tabular}{lcccccc}
\hline & \multicolumn{2}{c}{ Density at $25^{\circ} \mathrm{C}, \mathrm{g} / \mathrm{cm}^{3}$} & \multicolumn{2}{c}{ Refractive index $\left(n_{D}\right)$} & \multicolumn{2}{c}{ UNIQUAC structural parameter } \\
Component & This work & Literature & This work & Literature & $r$ & $q$ \\
\hline Dodecane & 0.745318 & $0.74523^{\mathrm{a}}$ & 1.419489 & $1.4196^{\mathrm{a}}$ & 8.5462 & 7.096 \\
Butanol & 0.806452 & $0.80558^{\mathrm{b}}$ & $1.397134^{\mathrm{b}}$ & 1.3972 & 3.4543 & 3.052 \\
Water & 0.997046 & $0.997048^{\mathrm{b}}$ & $1.332421^{\mathrm{b}}$ & 1.3325 & 0.92 & 1.4 \\
\hline
\end{tabular}

${ }^{a}$ Reference [35].

${ }^{\mathrm{b}}$ Reference [36].

the UNIQUAC interaction parameter for completely miscible pair.

The water-dodecane-butanol ternary LLE system was predicted using available binary experimental data (case A) and the COSMO-RS estimated activity coefficient data instead of experimental VLE data (case B). In both cases available experimental mutual solubility data were used to estimate the UNIQUAC interaction parameter for partially miscible pair. Special attention was paid to estimate the UNIQUAC interaction parameter from the mutual solubility data. UNIQUAC interaction parameters were estimated from the mutual solubility data based on the method proposed by Mitsos et al. [13]. In their work the phase stability constraint was satisfied along with the equality of activity in both phases. The UNIFAC group contribution method was also used to estimate the ternary LLE. The UNIFAC LLE parameter table given by Magnussen et al. [3] was used. The experimental and predicted results using UNIQUAC (case A and case B) and UNIFAC were compared.

\section{Experimental Methods}

Butanol and dodecane with a purity of $99 \%$ supplied by Loba Chemie and Sigma Aldrich, respectively, were used as received. The pure component density $(\rho)$ and refractive index $(\mathrm{nD})$ were measured at $298.15 \mathrm{~K}$ and given in Table 1. ASTM Grade-I water as per ASTM D-1193-99 (1999) with a resistivity of $18.2 \mathrm{M} \Omega \cdot \mathrm{cm}$ at $298.15 \mathrm{~K}$ and TOC $<15 \mathrm{ppb}$ from a MILLIPORE Simplicity system was used in the experiments.

The known amounts of dodecane, butanol, and water were weighed in the precision SHIMADZU AUW $220 \mathrm{~d}$ balance $(220 \mathrm{~g} / 82 \mathrm{~g}, 0.1 / 0.01 \mathrm{mg}$ resolution) and taken into $100 \mathrm{~mL}$ flask and stirred by magnetic stirrer for $3 \mathrm{hrs}$ and then allowed to settle for $12 \mathrm{hrs}$. After settling the samples were collected from both phases and centrifuged. The butanol concentrations present in the aqueous and organic samples were analyzed by refractometry and gas chromatography (GC), respectively. The density and refractive index were measured with Anton Paar DMA-5000 densitometer coupled with RXA-156 refractometer. The organic water concentration was determined by densimetry. The organic phase density was expressed as a function of water composition. The low concentration of butanol in the organic phase was analyzed by gas chromatography. In the cases of larger concentration of butanol, gravimetric method was employed.
TABLE 2: UNIQUAC interaction parameter $\left(a_{i j}\right)$ calculated using experimental VLE data and COSMO-RS activity coefficient data.

\begin{tabular}{lcccc}
\hline & \multicolumn{3}{c}{ Experimental (Case A) } & \multicolumn{2}{c}{ COSMO-RS (Case B) } \\
\hline Component & $a_{i j}{ }^{c}$ & $a_{j i}$ & $a_{i j}$ & $a_{j i}$ \\
Butanol-dodecane -105.05 & 352.18 & -145.86 & 535.426 \\
\hline
\end{tabular}

${ }^{\mathrm{c}} \tau_{i j}=\exp \left(-a_{i j} / T\right)$.

TABLE 3: UNIQUAC interaction parameter estimated from mutual solubility data and their RMSD (\%) in their estimation.

\begin{tabular}{lccc}
\hline Binary pair $(i-j)$ & $a_{i j}$ & $a_{j i}$ & RMSD (\%) \\
\hline Butanol-water & -5.896 & 265.97 & 0.469 \\
Dodecane-water & 1300 & 342 & 1.75 \\
\hline
\end{tabular}

\section{Calculation Method}

The UNIQUAC model was used to express the liquid phase activity coefficient. The group contribution model UNIFAC was used to find the ternary LLE composition and compared with the UNIQUAC prediction. The details of these models can be found in Abrams and Prausnitz [14] and Fredenslund et al. [15]. The UNIQUAC binary interaction parameters were estimated from the VLE and mutual solubility data of the constituent binary pairs. The experimental data selection and parameter estimation from the experimental mutual solubility data are discussed in Sections 3.1 and 3.2. The modified Rachford Rice algorithm [16] was used to estimate the ternary LLE phase compositions. The initial estimate of the phase compositions was provided as mole fraction and the corresponding equilibrium compositions were estimated. The liquid phase activity coefficient was estimated from the UNIQUAC and UNIFAC model. All the calculations were done at $298.15 \mathrm{~K}$.

3.1. Data Selection. A thorough literature survey was carried out to collect the VLE data of butanol-dodecane pair and mutual solubility data of dodecane-water and butanol-water. From the selected experimental data UNIQUAC binary interaction parameters were estimated. The selected final data and the estimated UNIQUAC binary interaction parameters are given in Tables 2 and 3. The experimental and estimated mutual solubility data using UNIFAC and UNIQUAC are shown in Table 4.

3.1.1. Butanol-Dodecane. For butanol-dodecane isothermal VLE data and UNIQUAC interaction parameter $\left(\tau_{i j}\right)$ 
TABLE 4: The experimental and calculated mutual solubility using UNIQUAC and UNIFAC.

\begin{tabular}{lcccccc}
\hline \multirow{2}{*}{ Binary pair $(i-j)$} & \multicolumn{2}{c}{ Solubility } & \multicolumn{2}{c}{$j$ in $i$} \\
& \multirow{2}{*}{ Exp. } & UnIQUAC (cases A and B) & UNIFAC & Exp. & UNIQUAC (cases A and B) & UNIFAC \\
\hline Dodecane-water & $4 \times 10^{-10}$ & $3.61 \times 10^{-8}$ & $3.56 \times 10^{-8}$ & $6.1 \times 10^{-4}$ & $1.19 \times 10^{-3}$ & $1.19 \times 10^{-3}$ \\
Butanol-water & 0.01896 & 0.01873 & 0.03169 & 0.51183 & 0.5052 & 0.5310 \\
\hline
\end{tabular}

reported by Belabbaci et al. [17] is available only at $313.15 \mathrm{~K}$. This UNIQUAC parameter $\left(\tau_{i j}\right)$ was used to calculate the binary interaction parameter $\left(a_{i j}\right)$ at $298.15 \mathrm{~K}$ using the relation $\tau_{i j}=\exp \left(a_{i j} / R T\right)$. The activity coefficient is estimated from the experimental data by using the following equation and the correction for vapor phase nonideality is not taken into account:

$$
\gamma_{i}=\frac{P \cdot y_{i}}{P_{i}^{o} \cdot x_{i}}
$$

3.1.2. Dodecane-Water. The dodecane-water pair has very low solubility of dodecane in water and vice versa. Shaw et al. [18] have compiled the solubility data of dodecane in water and water in dodecane. Franks [19] and Sutton and Calder [20] reported dodecane solubility in water at $298.2 \mathrm{~K}$. The value of $4 \times 10^{-10}$ for dodecane solubility in water and a value of $6.1 \times$ $10^{-4}$ for water solubility in dodecane reported by Sutton and Calder [20] and Schatzberg [21], respectively, were chosen.

3.1.3. Butanol-Water. 1-Butanol-water is partially miscible. The mutual solubility of butanol-water has been reported in literature [22-32]. The average value of 0.01896 was chosen among the literature reported solubility data [22-29] for the butanol solubility in water. The water solubility in butanol at $298.15 \mathrm{~K}$ was chosen as 0.51183 , which is the average value of the literature reported data [22-24, 26, 30-32].

3.2. Parameter Estimation. The UNIQUAC interaction parameter for the miscible pair in the ternary liquidliquid system was estimated using the literature reported experimental vapor liquid equilibrium data (case A) and also using the COMSO-RS generated activity coefficient data (case B). In case B, the activity coefficient data estimated using the COSMO-RS model implemented in COSMOtherm [33] software is used to estimate the UNIQUAC interaction parameter. In COSMO-RS estimation of activity coefficient, TZVP basis set cosmo database was used for all the components.

Estimation of binary interaction parameter for excess Gibbs free energy model such as UNIQUAC is a challenging task due to the nonlinear nature of the equation. The nonlinear equation to be solved for the binary parameter may have unknown number of solutions or no solution at all $[13,34]$. In order to predict the ternary liquid-liquid equilibrium, we need to determine the unique binary parameter for the given binary. So the method proposed by Mitsos et al. [13] was used to estimate the binary UNIQUAC interaction parameter from

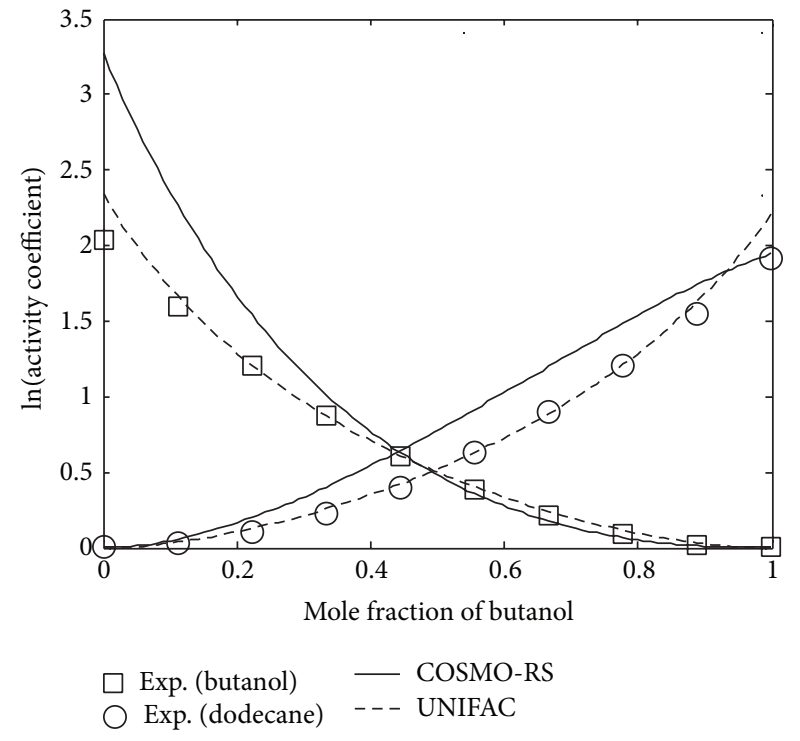

FIGURE 1: The comparison of experimental and model predicted activity coefficient of butanol and dodecane.

the mutual solubility data. In this method additional phase stability condition was satisfied along with the equality of activity condition.

\section{Results and Discussion}

Experimental and predicted activity coefficient of butanoldodecane using COSMO-RS and UNIFAC model was shown in Figure 1. The UNIQUAC interaction parameter calculated using mutual solubility data is given in Table 3 . The Gibbs tangent plane diagram using UNIQUAC model for the systems dodecane-water and butanol-water is shown in Figures 2 and 3 , respectively. The measured density and refractive index for the aqueous and organic phase are listed in Table 5. The experimentally determined composition in the aqueous and organic phase is shown in Table 6 .

According to Figure 1 the UNIFAC estimated activity coefficient for butanol-dodecane is closely matching with the experimental data. In butanol activity coefficient significant deviation was observed between the COSMO-RS estimated and experimental data at concentration below 0.5 mole fraction. At higher concentrations the COSMO-RS predicted activity coefficient matches well with the experimental data. 
TABLE 5: Measured density and refractive index of water-dodecane-butanol ternary system.

\begin{tabular}{|c|c|c|c|c|c|c|c|}
\hline \multicolumn{4}{|c|}{ Aqueous phase } & \multicolumn{4}{|c|}{ Organic phase } \\
\hline \multicolumn{2}{|c|}{ Mole fraction } & \multirow{2}{*}{ Density at $25^{\circ} \mathrm{C}, \mathrm{g} / \mathrm{cm}^{3}$} & \multirow{2}{*}{ Refractive index } & \multicolumn{2}{|c|}{ Mole fraction } & \multirow{2}{*}{ Density at $25^{\circ} \mathrm{C}, \mathrm{g} / \mathrm{cm}^{3}$} & \multirow{2}{*}{ Refractive index } \\
\hline Water & Butanol & & & Water & Butanol & & \\
\hline 0.9913 & 0.0087 & 0.9923 & 0.7455 & 0.0258 & 0.0179 & 0.7455 & 1.4192 \\
\hline 0.9967 & 0.0033 & 0.9953 & 0.7453 & 0.035 & 0.0024 & 0.7453 & 1.4194 \\
\hline 0.9913 & 0.0087 & 0.9923 & 0.7455 & 0.0273 & 0.0149 & 0.7455 & 1.4192 \\
\hline 0.982 & 0.018 & 0.9874 & 0.7716 & 0.2254 & 0.4435 & 0.7716 & 1.4085 \\
\hline 0.9826 & 0.0174 & 0.9876 & 0.7653 & 0.167 & 0.4116 & 0.7653 & 1.4107 \\
\hline 0.9829 & 0.0171 & 0.9878 & 0.7623 & 0.1419 & 0.3826 & 0.7623 & 1.4118 \\
\hline 0.9899 & 0.0101 & 0.9914 & 0.7456 & 0.0248 & 0.0221 & 0.7456 & 1.4191 \\
\hline 0.9831 & 0.0169 & 0.9879 & 0.7799 & 0.2858 & 0.4744 & 0.7799 & 1.4058 \\
\hline 0.9829 & 0.0171 & 0.9878 & 0.7672 & 0.1849 & 0.4228 & 0.7672 & 1.4101 \\
\hline
\end{tabular}

TABLE 6: Experimental ternary data for water-dodecane-butanol (in mole fraction).

\begin{tabular}{lcccccccc}
\hline \multicolumn{3}{c}{ Overall mole fraction } & \multicolumn{3}{c}{ Aqueous phase } \\
Water & Butanol & Dodecane & Water & Butanol & Dodecane & Water & $\begin{array}{c}\text { Organic phase } \\
\text { Butanol }\end{array}$ & Dodecane \\
\hline 0.5986 & 0.0125 & 0.3889 & 0.9913 & 0.0087 & 0.0000 & 0.0258 & 0.0179 \\
0.5008 & 0.0029 & 0.4963 & 0.9967 & 0.0033 & 0.0000 & 0.0350 & 0.0024 \\
0.5031 & 0.0119 & 0.4850 & 0.9913 & 0.0087 & 0.0000 & 0.0273 & 0.0149 \\
0.5991 & 0.2340 & 0.1669 & 0.9820 & 0.0180 & 0.0000 & 0.2254 & 0.4435 \\
0.5850 & 0.2101 & 0.2049 & 0.9826 & 0.0174 & 0.0000 & 0.1670 & 0.4116 & 0.9626 \\
0.6574 & 0.1589 & 0.1837 & 0.9829 & 0.0171 & 0.0000 & 0.1419 & 0.3826 \\
0.5073 & 0.0162 & 0.4765 & 0.9899 & 0.0101 & 0.0000 & 0.0248 & 0.0221 \\
0.6244 & 0.2530 & 0.1227 & 0.9831 & 0.0169 & 0.0000 & 0.2858 & 0.4744 \\
0.6688 & 0.1772 & 0.1539 & 0.9829 & 0.0171 & 0.0000 & 0.1849 & 0.475 \\
\hline
\end{tabular}

In the estimation of dodecane activity coefficient, COSMORS values were closer to the experimental data at infinite dilution and higher concentration region; in other places the estimated values were higher than the experimental data. As UNIFAC group contributions were estimated from experimental data, it resulted in a better prediction of the activity coefficient as compared with a-priory prediction by COSMO-RS.

Figure 2 shows that the Gibbs energy of mixing is positive for dodecane-water system for the entire concentration range due to its very low mutual solubility limits. Butanol-water is partially miscible, the solubility of water in the organic phase is higher as compared to the aqueous solubility. So the Gibbs energy of mixing plot shows highly negative region in the butanol rich region as shown in Figure 3. The butanol-water shows maximum miscibility gap of mole fraction of 0.5 .

The comparison of model predicted and experimental LLE mole fraction is shown in Figure 4. In Figure 5 the experimental distribution of butanol in the dilute region is shown along with the model predictions. From Figure 4, it is clear that all the models overpredict the water-dodecanebutanol equilibrium composition while UNIQUAC (case A and case $\mathrm{B}$ ) predicted values were closer to the experimental values than the UNIFAC estimation. The value of distribution coefficient of butanol estimated by various models is significantly different. The predicted values of the butanol distribution coefficient were $8.58,2.05$, and 12.80 , respectively,

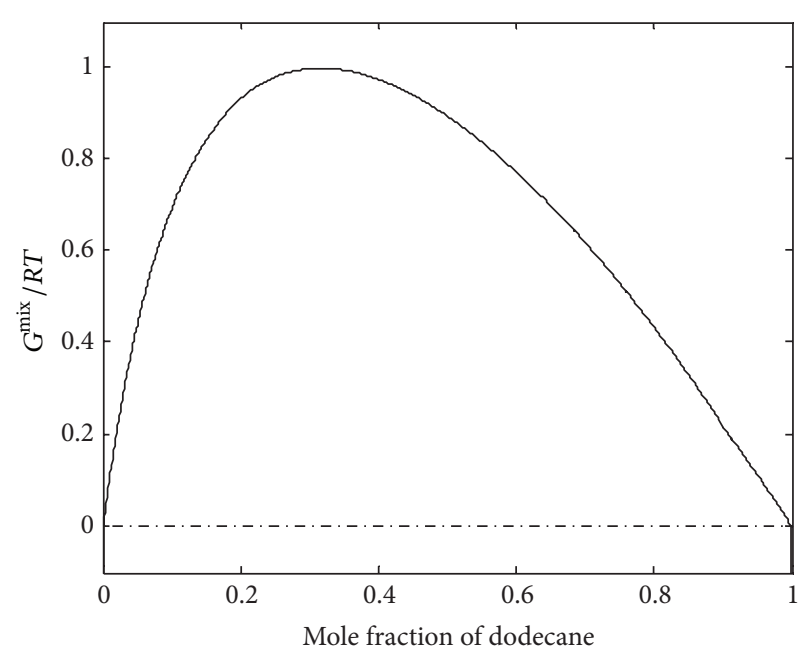

FIGURE 2: Gibbs tangent plane diagram for the system dodecanewater at $298.15 \mathrm{~K}$.

for UNIQUAC (case A and case B) and UNIFAC model. The RMSD (\%) between the experimental and calculated butanol distribution in the dilute region is $4.95,0.247$, and 7.63, respectively, for UNIQUAC (case A and case B) and UNIFAC. 


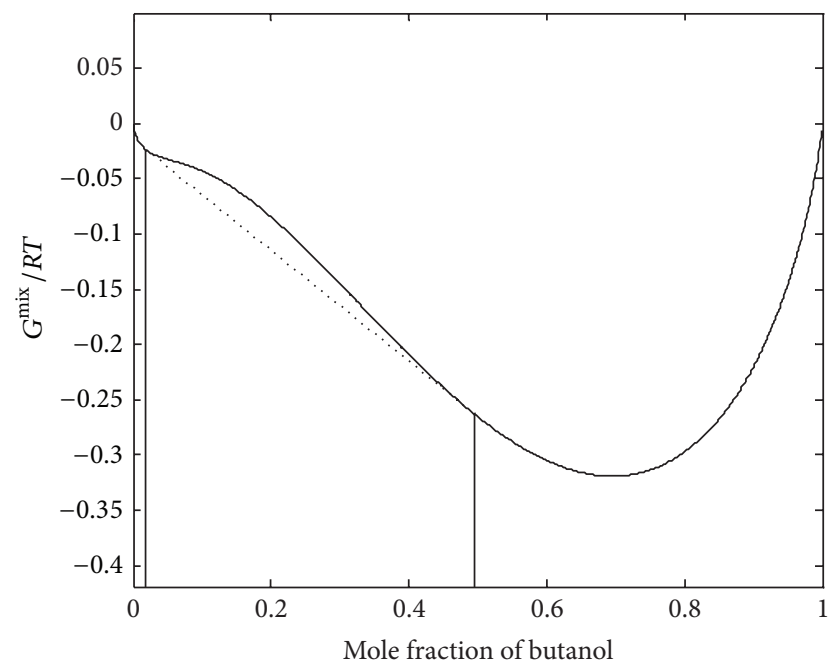

FIGURE 3: Gibbs tangent plane diagram for the system butanol-water at $298.15 \mathrm{~K}$

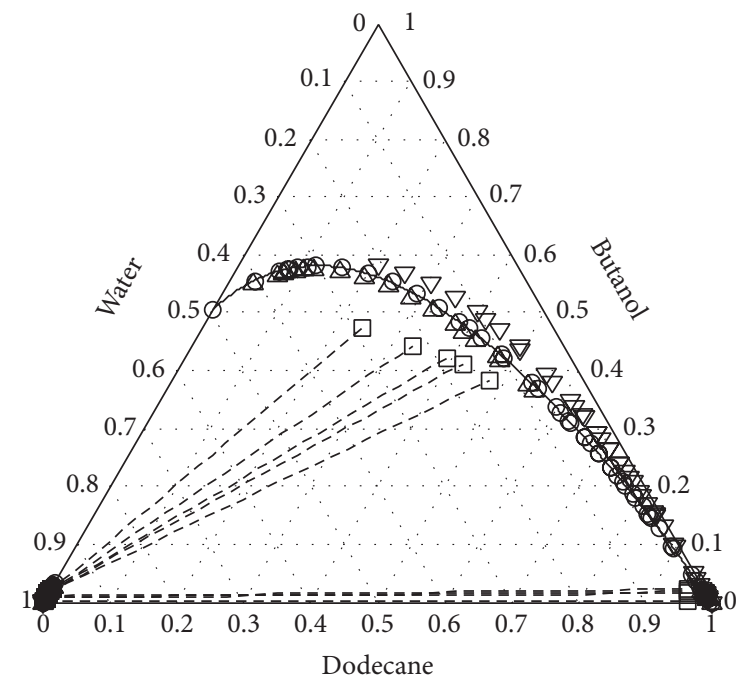

FIGURE 4: LLE for the ternary system water-dodecane-butanol at 298.15 K. $\square$ : experimental data; O: UNIQUAC (case A) calculated; $\triangle$ : UNIQUAC (case B) calculated; $\nabla$ : UNIFAC calculated; dotted lines are tie lines from experimental data.

\section{Conclusion}

The water-dodecane-butanol liquid-liquid equilibrium composition is experimentally measured at $298.15 \mathrm{~K}$. This ternary LLE data was predicted from their binary experimental data using UNIQUAC model. The LLE composition is also predicted using the COSMO-RS estimated activity coefficient for the miscible pair (butanol-dodecane) along with experimental mutual solubility data. The UNIQUAC prediction is slightly better than the UNIFAC prediction. All the models overpredict the heterogeneous region at the butanol rich side of the ternary system. The RMSD (\%) for the prediction of butanol distribution using COSMO-RS calculated activity coefficient along with the experimental mutual solubility data

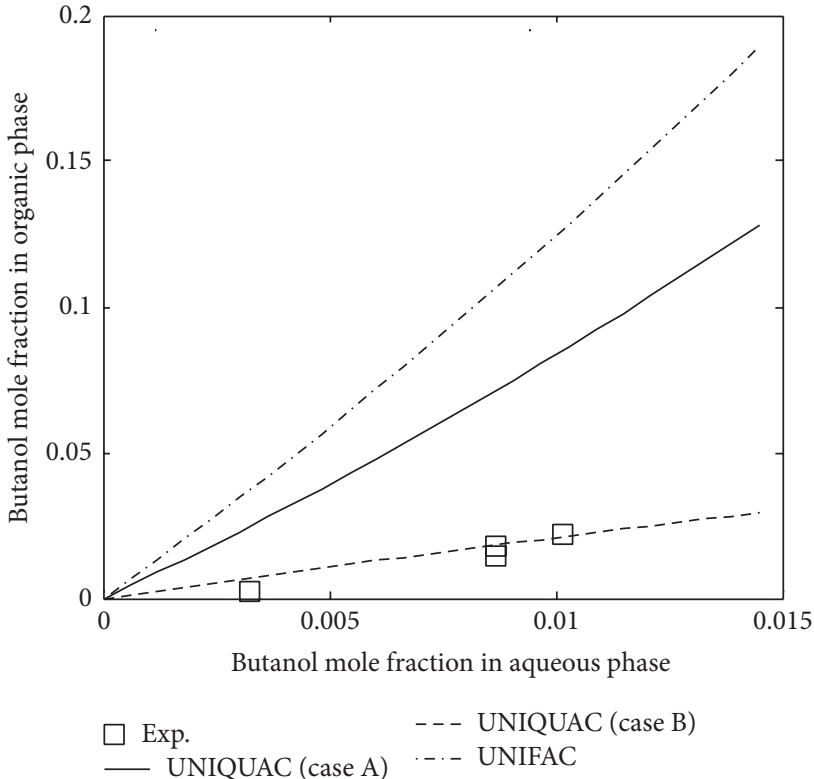

FIGURE 5: Distribution of butanol between aqueous and organic phase at $298.15 \mathrm{~K}$.

is $0.24 \%$. The accuracy of the ternary LLE prediction depends on the accuracy of binary VLE prediction.

\section{Conflict of Interests}

The authors declare that there is no conflict of interests regarding the publication of this paper.

\section{References}

[1] A. Wright and P. P. Hartmann, "Review of physical and chemical properties of tributyl phosphate/diluent/nitric acid systems," Separation Science and Technology, vol. 45, no. 12, pp. 1753-1762, 2010.

[2] T. F. Anderson and J. M. Prausnitz, "Application of the UNIQUAC equation to calculation of multicomponent phase equilibria. 2. Liquid-liquid equilibria," Industrial \& Engineering Chemistry Process Design and Development, vol. 17, no. 4, pp. 561-567, 1978.

[3] T. Magnussen, P. Rasmussen, and A. Fredenslund, "UNIFAC parameter table for prediction of liquid-liquid equilibria," Industrial \& Engineering Chemistry Process Design and Development, vol. 20, no. 2, pp. 331-339, 1981.

[4] I. Nagata and K. Katoh, "Effective UNIQUAC equation in phase equilibrium calculation," Fluid Phase Equilibria, vol. 5, no. 3-4, pp. 225-244, 1981.

[5] I. Nagata, "Prediction of Ternary phase equilibria from binary data," Thermochimica Acta, vol. 56, no. 1, pp. 43-57, 1982.

[6] A. Klamt and F. Eckert, "COSMO-RS: a novel and efficient method for the a priori prediction of thermophysical data of liquids," Fluid Phase Equilibria, vol. 172, no. 1, pp. 43-72, 2000.

[7] F. Eckert and A. Klamt, "Fast solvent screening via quantum chemistry: COSMO-RS approach," AIChE Journal, vol. 48, no. 2, pp. 369-385, 2002. 
[8] Y. Shimoyama, Y. Iwai, S. Takada, Y. Arai, T. Tsuji, and T. Hiaki, "Prediction of phase equilibria for mixtures containing water, hydrocarbons and alcohols at high temperatures and pressures by cubic equation of state with $G^{\mathrm{E}}$ type mixing rule based on COSMO-RS," Fluid Phase Equilibria, vol. 243, no. 1-2, pp. 183192, 2006.

[9] T. Banerjee, R. K. Sahoo, S. S. Rath, R. Kumar, and A. Khanna, "Multicomponent liquid-liquid equilibria prediction for aromatic extraction systems using COSMO-RS," Industrial \& Engineering Chemistry Research, vol. 46, no. 4, pp. 1292-1304, 2007.

[10] M. G. Freire, S. P. M. Ventura, L. M. N. B. F. Santos, I. M. Marrucho, and J. A. P. Coutinho, "Evaluation of COSMO-RS for the prediction of LLE and VLE of water and ionic liquids binary systems," Fluid Phase Equilibria, vol. 268, no. 1-2, pp. 7484,2008 .

[11] A. W. Islam, A. Javvadi, and V. N. Kabadi, "Universal liquid mixture models for Vapor-Liquid and Liquid-Liquid equilibria in the Hexane-Butanol-Water system," Industrial \& Engineering Chemistry Research, vol. 50, no. 2, pp. 1034-1045, 2011.

[12] Y. Iwai and Y. Yamamoto, "Concentration dependent surface area parameter model for calculation of activity coefficients," Fluid Phase Equilibria, vol. 337, pp. 165-173, 2013.

[13] A. Mitsos, G. M. Bollas, and P. I. Barton, "Bilevel optimization formulation for parameter estimation in liquid-liquid phase equilibrium problems," Chemical Engineering Science, vol. 64, no. 3, pp. 548-559, 2009.

[14] D. S. Abrams and J. M. Prausnitz, "Statistical thermodynamics of liquid mixtures: a new expression for the excess gibbs energy of partly or completely miscible systems," AIChE Journal, vol. 21, no. 1, pp. 116-128, 1975.

[15] A. Fredenslund, R. L. Jones, and J. M. Prausnitz, "Groupcontribution estimation of activity coefficients in non ideal liquid mixtures," AIChE Journal, vol. 21, no. 6, pp. 1086-1099, 1975.

[16] J. D. Seader and E. J. Henley, Separation Process Principles, Wiley, New York, NY, USA, 1960.

[17] A. Belabbaci, R. M. Villamanan, L. Negadi, C. M. Martin, A. A. Kaci, and M. A. Villamanan, "Vapor-liquid equilibria of binary mixtures containing 1-Butanol and hydrocarbons at 313.15K," Journal of Chemical and Engineering Data, vol. 57, no. 1, pp. 114119, 2012.

[18] D. G. Shaw, A. Maczynski, M. Goral et al., "IUPAC-NIST solubility data series. 81 . Hydrocarbons with water and seawaterrevised and updated-part 10: $C_{11}$ and $C_{12}$ hydrocarbons with water," Journal of Physical and Chemical Reference Data, vol. 35, no. 1, p. 153, 2006.

[19] F. Franks, "Solute-water interactions and the solubility behaviour of long-chain paraffin hydrocarbons," Nature, vol. 210, pp. 87-88, 1966.

[20] C. Sutton and J. A. Calder, "Solubility of higher-molecularweight normal-paraffins in distilled water and sea water," Environmental Science and Technology, vol. 8, no. 7, pp. 654-657, 1974.

[21] P. Schatzberg, "Solubilities of water in several normal alkanes from $\mathrm{C}_{7}$ to $\mathrm{C}_{16}^{1}$ ", The Journal of Physical Chemistry, vol. 67, no. 4, pp. 776-779, 1963.

[22] J. A. V. Butler, D. W. Thomson, and W. H. Maclennan, “The free energy of the normal aliphatic alcohols in aqueous solutionpart I: the partial vapour pressures of aqueous solutions of methyl, $n$-propyl, and $n$-butyl alcohols-part II: the solubilities of some normal aliphatic alcohols in water-part III: the theory of binary solutions, and its application to aqueous-alcoholic solutions," Journal of the Chemical Society, pp. 674-686, 1933.

[23] R. de Santis, L. Marrelli, and P. N. Muscetta, "Liquid-liquid equilibria in water-aliphatic alcohol systems in the presence of sodium chloride," The Chemical Engineering Journal, vol. 11, no. 3, pp. 207-214, 1976.

[24] V. Gomis-Yagues, F. Ruiz-Bevia, M. Ramos-Nofuentesand, and M. J. Fernandez-Torres, "The influence of the temperature on the liquid-liquid equilibrium of the ternary system 1-butanol1-propanol-water," Fluid Phase Equilibria, vol. 149, no. 1-2, pp. 139-145, 1998.

[25] R. S. Hansen, Y. Fu, and F. E. Bartell, "Multimolecular adsorption from binary liquid solutions," The Journal of Physical Chemistry, vol. 53, no. 6, pp. 769-785, 1949.

[26] A. E. Hill and W. M. Malisoff, "The mutual solubility of liquids. III. The mutual solubility of phenol and water. IV. The mutual solubility of normal butyl alcohol and water," Journal of the American Chemical Society, vol. 48, no. 4, pp. 918-927, 1926.

[27] K. Kinoshita, H. Ishikawa, and K. Shinoda, "Solubility of alcohols in water determined by the surface tension measurements," Bulletin of the Chemical Society of Japan, vol. 31, pp. 1081-1082, 1958.

[28] B. Marongiu, I. Ferino, R. Monaci, V. Solinas, and S. Torrazza, "Thermodynamic properties of aqueous non-electrolyte mixtures. Alkanols+water systems," Journal of Molecular Liquids, vol. 28, no. 4, pp. 229-247, 1984.

[29] M. I. Perl, A. Kisfaludi, and P. M. Szakacs, "Composition of ternary systems comprising water, n-butyl or isobutyl alcohol, and one of the four mineral acids $\mathrm{HClO} 4, \mathrm{HNO} 3, \mathrm{HCl}$ or H2SO4," Journal of Chemical \& Engineering Data, vol. 29, no. 1, pp. 66-69, 1984.

[30] F. Ruiz, M. I. Galan, and N. Boluda, "Quaternary liquid-liquid equilibrium: water-phosphoric acid-1-butanol-2-butanone at $25^{\circ}$ C," Fluid Phase Equilibria, vol. 146, no. 1-2, pp. 175-185, 1998.

[31] A. C. G. Marigliano, M. B. G. de Doz, and H. N. Solimo, "Influence of temperature on the liquid-liquid equilibria containing two pairs of partially miscible liquids: water+furfural+1-butanol ternary system," Fluid Phase Equilibria, vol. 153, no. 2, pp. 279292, 1998.

[32] L. Lintomen, R. T. P. Pinto, E. Batista, A. J. A. Meirelles, and M. R. W. Maciel, "Liquid-liquid equilibrium of the water + citric Acid + short chain alcohol + tricaprylin system at $298.15 \mathrm{~K}$," Journal of Chemical and Engineering Data, vol. 46, no. 3, pp. 546-550, 2001.

[33] F. Eckert and A. Klamt, COSMOtherm, Version C2. 1, Release 01. 11, COSMOlogic, GmbH \& Co. KG, Leverkusen, Germany, 2010.

[34] J. P. Novak, J. Matous, and J. Pick, Liquid-Liquid Equilibria, Elsevier, Amsterdam, The Netherlands, 1987.

[35] C. H. Su, S. Y. Lin, and L. J. Chen, "(Liquid + liquid) equilibria for the ternary system (water + dodecane + propylene glycol npropyl ether)," Journal of Chemical Thermodynamics, vol. 47, pp. 358-361, 2012.

[36] A. M. Farhan and A. M. Awwad, "Relative permittivities, refractive indices, and densities of dihydrofuran-2(3H)-one + butan-1-ol and + butan-2-ol at $T=(293.15,298.15,303.15$, and 313.15) K," Journal of Chemical and Engineering Data, vol. 55, no. 2, pp. 1035-1038, 2010. 

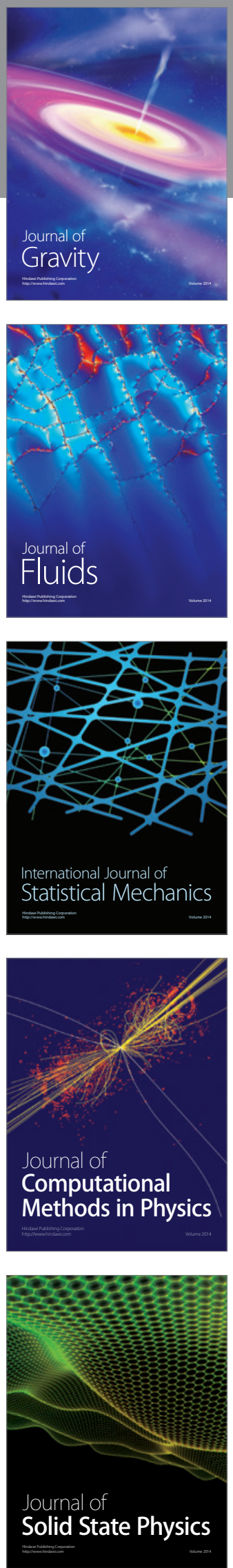

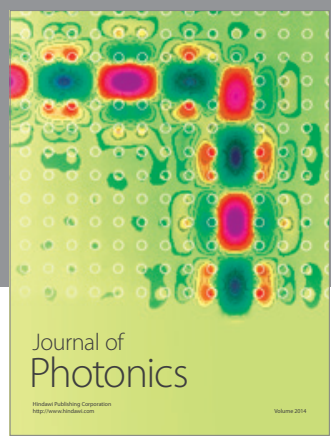

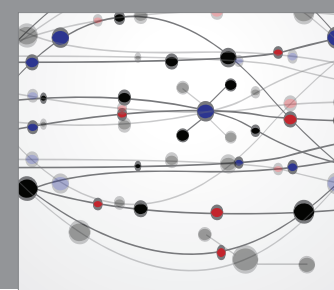

The Scientific World Journal

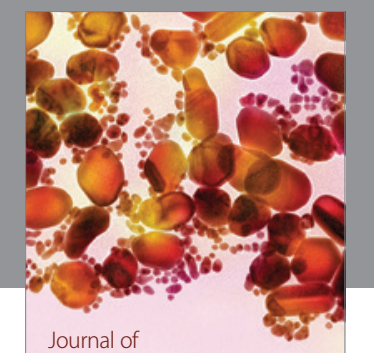

Soft Matter
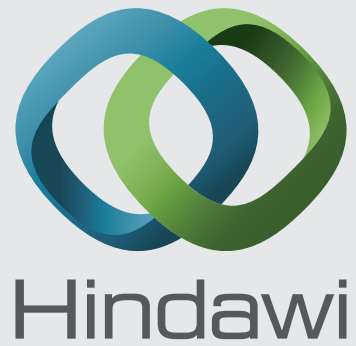

Submit your manuscripts at

http://www.hindawi.com
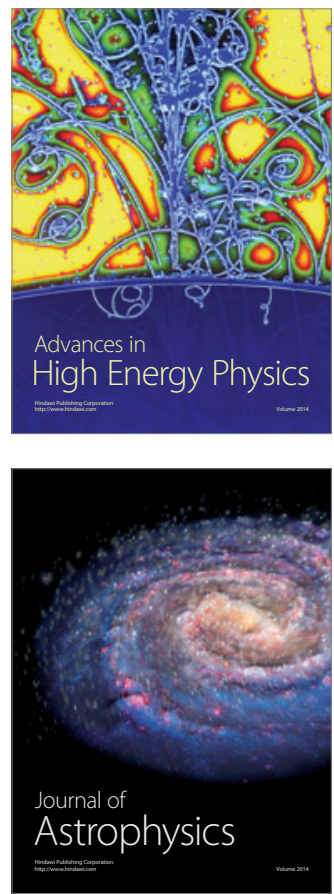
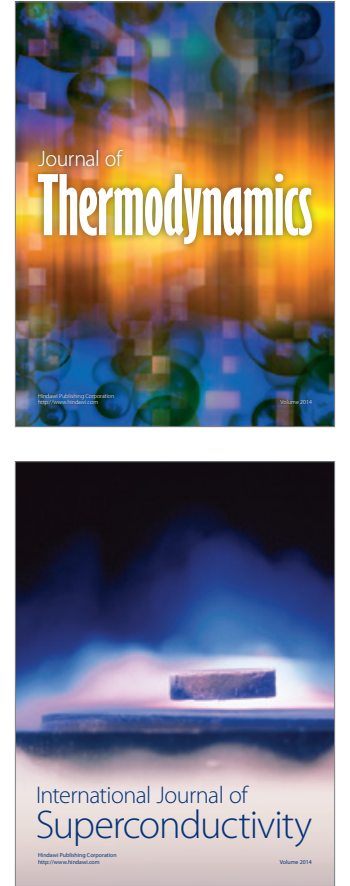
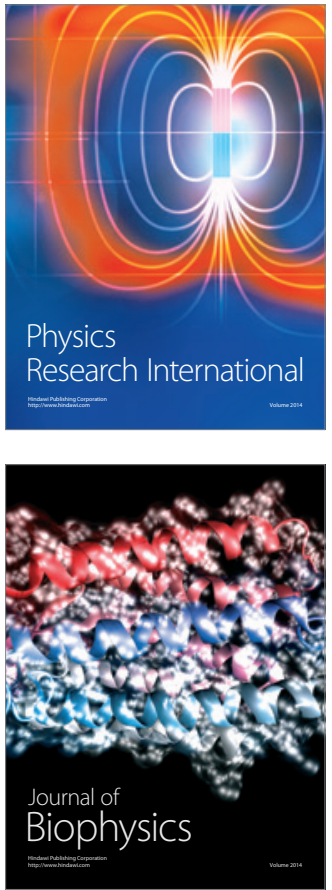
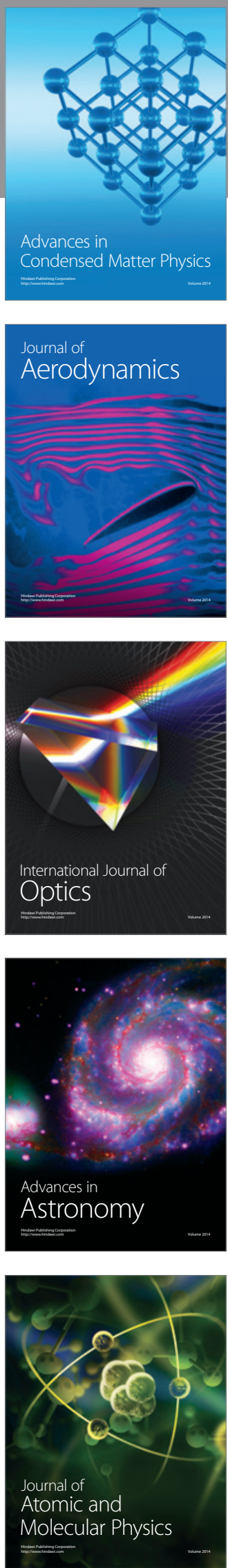